\title{
Seasonal Anomalies: A Closer Look at the Johannesburg Stock Exchange
}

\author{
Ali F. Darrat \\ Louisiana Tech University \\ E-Mail: yarab@latech.edu \\ Bin Li \\ Griffith University \\ E-Mail: b.li@griffith.edu.au \\ Richard Chung \\ Griffith University \\ E-Mail: r.chung@griffith.edu.au
}

\begin{abstract}
We examine seasonal anomalies in Johannesburg daily stock returns from January 1973 to September 2012. This paper focuses on three seasonal effects: day-of-the-week, beginning-of-the-month and month-of-the-year. We found no compelling evidence for either a January or December effect in the South African market. Instead, our results support the presence of strong Monday and Tuesday effects, whereby the returns on Monday and Tuesday are significantly lower than the return on the benchmark day of Wednesday. Moreover, the beginning-of-the-month effect is quite pronounced in which second and third trading day returns are significantly larger than returns in other trading days. Nevertheless, these strong day-of-the-week and beginning-of-the-month seasonal effects disappear in the post-2008 period following the global financial crisis. It appears that the South African stock market may have filtered out seasonal anomalies and become more efficient in the aftermath of the recent global financial crisis.
\end{abstract}

Keywords: Seasonal anomalies, market efficiency, global financial crisis, Johannesburg Stock Exchange

JEL Classifications: G14, C12 


\section{INTRODUCTION}

The efficient market hypothesis implies that investors cannot use past information to reap abnormal returns if the market is efficient. However, research dating back at least to Kemmerer (1911) has long shown the presence of seasonal anomalies in equity markets at various time frequencies which opens the possibilities for profitable trading strategies.

Among the most popular calendar effects is day-of-the-week, especially the Monday effect. Keim \& Stambaugh (1984), and Cho, Linton, \& Whang (2007), among others, found that Mondays display significantly negative average returns in the US stock market. Jaffe \& Westerfield (1985) report similar anomalies in international equity markets. Another well-known effect is the beginning-of-the-month effect wherein stock returns are reportedly higher during the first few trading days of the month (Tonchev \& Kim, 2004; Worthington, 2010). In addition, research also reveals some patterns for a month-of-the-year effect, where returns in some months are significantly larger/lower than returns in other months. Among these, the January effect is most notably where stock returns in January appear significantly greater than returns in other months of the year (Gultekin \& Gultekin, 1983; Ariel, 1987; Dzhabarov \& Ziemba, 2010). However, a recent study by Darrat, Li, Liu, \& Su (2012) found no support for the January effect in thirty-four international markets. Instead, they found a strong December effect among most of the markets in their sample.

Seasonality in stock markets is an intriguing issue despite extensive research, the evidence remains mixed. The presence of seasonality in stock returns should appeal to a wide range of market participants, such as portfolio managers and individual investors, in their search for when to buy or sell stocks. Knowledge on seasonality may also help listed companies and private firms as to the timing for issuing new shares.

This paper investigates seasonal effects in the Johannesburg Stock Exchange (JSE), the largest stock market in Africa. Since its inception in 1887, the JSE has played a central role in financial and capital market developments in South Africa over the past 120 years (JSE, 2012). At the end of December 2011, the JSE enlisted more than 400 companies with an annual trading value of US $\$ 372$ billion and a market capitalization of US $\$ 789$ billion, making the JSE the 17th largest stock exchange in the world. Due to its rapid economic development, South Africa was listed in December 2010 as a leading emerging economy joining the group consisting of Brazil, Russia, India and China (BRIC), a group that could possess $40 \%$ of global 
wealth by 2020 and may surpass the G7 economies by 2027 (Wikipedia). It is estimated that $10 \%$ of the world's oil reserves and $40 \%$ of the world's proven gold reserves are found in Africa. A recent study finds that the average return on capital of African companies was $70 \%$ higher than that of the companies in China and India over the period from 2002 to 2007. However, the average P/E for African companies is much lower than that of the S\&P 500, thus providing valuable investment opportunities for global investors (Baden 2010). Since South Africa likely constitutes a significant component of global fund portfolios and investment opportunities, a deeper understanding of the seasonality pattern should prove useful for fund managers and global investors.

Despite the importance of South Africa in the global market, research on seasonal effects in the JSE is sparse. Among the few exceptions, Alagidede (2008a) examined the day-of-the-week effect in South Africa and reported higher Monday returns for the period 2001-2006. Alagidede (2008b) also investigated the month-of-the-year effect in South Africa and found higher February returns over the period 1997-2006. Lucey (2001) examined the Friday the 13th anomaly in several countries and reported statistically lower returns for Friday the 13th in South Africa. Coutts and Sheikh (2002) searched for weekend and January effects in South Africa for the period 1987-1997, reporting none.

We examined the presence of seasonal effects in the South African market using daily data from January 1, 1973 to September 28, 2012. We examined three types of seasonal effects: day-of-the-month, beginning-of-the-month, and month-of-the-year. We employed the GARCH framework to model the variance process. Our study differs from prior research on the seasonal effects in South Africa in at least three main aspects. First, unlike other studies that are based on shorter samples of 5-10 years, we covered a much longer history of stock returns spanning almost 40 years (1973 to 2012), which should increase the power of our tests. Second, we also investigated the "beginning-of-month" effect specifically for the South African stock market, which has not been examined in prior research. Third, we addressed all three types of seasonality in a single study (day-of-the-week, beginning-of-the-month, and month-of-the-year), while previous studies examined only one of these effects.

Section 2 describes the data used, while Section 3 outlines the methodology. Section 4 presents the empirical findings and Section 5 concludes. 


\section{DATA}

Our data consisted of the daily total return index of the Johannesburg stock exchange obtained from DataStream (Code: TOTMKSA). The sample covers January 1, 1973 through September 28, 2012, producing 10,370 daily observations. Daily market returns (in percentage terms) are computed as $100 \times$ the log difference of the market index at day $t$ and day $t-1$ :

$$
R_{t}=100 \times \ln \left(P_{t} / P_{t-1}\right)
$$

Table 1 provides the summary statistics for the daily market returns. The statistics include the number of observations, mean, median, minimum, maximum, standard deviation, skewness, kurtosis, and the Jarque-Bera statistics for the daily returns in different calendar categories. As the table suggests, mean returns on Monday (nearly 0), Tuesday (0.03\%), and Friday (0.04\%) are much lower than the mean return on Wednesday (0.16\%) Interestingly, the mean return on the second trading day of the week $(0.24 \%)$ is quite a bit larger than those on the first and third trading days ( $0.10 \%$ and $0.11 \%$, respectively). The table also shows that the monthly mean returns are very similar across years except for December which has a higher return (0.17\%). In addition to higher returns, December also generally displays lower standard deviations. The Jarque-Bera statistics suggested that daily returns are clearly not normally distributed, implying that the standard regression method is not suitable in this case.

\section{METHODOLOGY}

We followed the methodology of Worthington (2010) to analyze seasonal effects. However, instead of linear regressions, we used the Generalized Autoregressive Conditional Heteroskedasticity (GARCH) approach to model the variance. We used a GARCH $(1,1)$ model with conditional normal distributions.

To analyze the day-of-the-week effect, we followed Worthington (2010) and specified the mean equation as:

$$
R_{t}=\alpha_{0}+\sum_{i=1}^{4} \alpha_{i} W_{i, t}+\varepsilon_{t}
$$


where $W_{i, t}$ is a dummy variable equal to 1 when it is day $\mathrm{i}$ and 0 otherwise (where $\mathrm{i}=1$, 2, 3, 4, and the benchmark is Wednesday), $\alpha$ are the estimated coefficients, and $\varepsilon_{t}$ is not normally distributed and follows the GARCH(1,1) process in:

$$
h_{t}=c+a \cdot \varepsilon_{t-1}^{2}+b \cdot h_{t-1}
$$

where $h_{t}$ is a conditional variance. Sun and Tong (2010) also used GARCH $(1,1)$ to model the variance process in examining the January effect. We employed the maximum likelihood method to estimate the parameters in all models in this paper.

Table 1 Summary Statistics of Daily Stock Returns (Jan.1, 1973 to Sept. 28, 2012)

\begin{tabular}{|c|c|c|c|c|c|c|c|c|c|c|}
\hline Variable & Number & Mean & Median & Std.Dev. & Min & Max & Skewness & Kurtosis & $\begin{array}{c}\text { JB } \\
\text { Statistics }\end{array}$ & $\begin{array}{c}\mathrm{JB} \\
\mathrm{p} \text {-value }\end{array}$ \\
\hline Monday & 2073 & 0.00 & 0.02 & 1.40 & -11.14 & 13.60 & -0.39 & 10.77 & 10079 & 0.00 \\
\hline Tuesday & 2074 & 0.03 & 0.03 & 1.34 & -14.52 & 5.69 & -1.43 & 14.19 & 18101 & 0.00 \\
\hline Wednesday & 2074 & 0.16 & 0.11 & 1.33 & -10.55 & 7.86 & -0.47 & 6.27 & 3473 & 0.00 \\
\hline Thursday & 2074 & 0.11 & 0.08 & 1.23 & -8.35 & 5.72 & -0.40 & 3.56 & 1154 & 0.00 \\
\hline Friday & 2074 & 0.04 & 0.03 & 1.14 & -8.60 & 6.35 & -0.30 & 4.80 & 2024 & 0.00 \\
\hline First & 477 & 0.10 & 0.02 & 1.26 & -6.09 & 4.56 & -0.60 & 3.21 & 234 & 0.00 \\
\hline Second & 477 & 0.24 & 0.20 & 1.26 & -6.89 & 6.42 & 0.00 & 4.01 & 319 & 0.00 \\
\hline Third & 477 & 0.11 & 0.16 & 1.33 & -7.60 & 4.62 & -0.84 & 3.91 & 359 & 0.00 \\
\hline January & 885 & 0.05 & 0.02 & 1.34 & -7.47 & 7.29 & -0.05 & 4.62 & 786 & 0.00 \\
\hline February & 807 & 0.06 & 0.10 & 1.28 & -8.88 & 5.69 & -0.61 & 4.86 & 844 & 0.00 \\
\hline March & 886 & 0.09 & 0.08 & 1.26 & -5.41 & 5.07 & -0.32 & 1.91 & 150 & 0.00 \\
\hline April & 857 & 0.07 & 0.02 & 1.14 & -8.36 & 5.43 & -0.63 & 5.45 & 1118 & 0.00 \\
\hline May & 886 & 0.08 & 0.03 & 1.11 & -5.28 & 4.29 & -0.22 & 2.11 & 171 & 0.00 \\
\hline June & 857 & 0.03 & 0.04 & 1.17 & -6.39 & 5.51 & -0.24 & 2.99 & 327 & 0.00 \\
\hline July & 885 & 0.08 & 0.11 & 1.12 & -3.82 & 5.20 & 0.09 & 1.64 & 101 & 0.00 \\
\hline August & 887 & 0.06 & 0.08 & 1.26 & -7.68 & 5.11 & -0.97 & 5.41 & 1221 & 0.00 \\
\hline September & 856 & 0.00 & 0.03 & 1.51 & -10.55 & 13.60 & -0.03 & 12.95 & 5982 & 0.00 \\
\hline October & 863 & 0.03 & 0.06 & 1.66 & -14.52 & 7.86 & -2.19 & 17.00 & 11076 & 0.00 \\
\hline November & 836 & 0.08 & 0.06 & 1.36 & -8.35 & 7.93 & -0.17 & 5.61 & 1099 & 0.00 \\
\hline December & 864 & 0.17 & 0.03 & 1.16 & -5.04 & 6.35 & -0.04 & 3.17 & 361 & 0.00 \\
\hline
\end{tabular}

Note: Returns are multiplied by 100 and expressed in local currency. 
For the day-of-the-week effect, we used the following mean equation:

$$
R_{t}=\beta_{0}+\sum_{j=1}^{3} \beta_{j} D_{i, t}+\phi_{t}
$$

where $D_{i, t}$ is a dummy variable equal to 1 if it is trading day $\mathrm{j}$ and zero otherwise (where $j=1,2,3$, and the benchmark is all other trading after the first trading days in that month). The variance process is specified as above.

The month-of-the-year effect was examined using the following equation:

$$
R_{t}=\chi_{0}+\sum_{k=1}^{11} \chi_{j} D_{k, t}+\varphi_{t}
$$

where $D_{k, t}$ is a dummy variable equal to 1 if it is month $k$ and zero otherwise (where $k=1,2,3,4,5,6,8,9,10,11,12$ and the benchmark is the month of July).

Finally, we combined the effects of day-of-the-week, beginning-of-the-month, and month-of-the-year into a single equation, calling it the calendar effect, with a mean equation specified as:

$$
R_{t}=\delta_{0}+\sum_{i=1}^{4} \alpha_{i} W_{i, t}+\sum_{j=1}^{3} \beta_{j} D_{i, t}+\sum_{k=1}^{11} \chi_{j} D_{k, t}+\gamma_{t}
$$

\section{EMPIRICAL RESULTS}

Table 2 presents the estimation results for the models considered in the previous section for the daily observations from January 1, 1973 to September 28, 2012. The table only reports the coefficient estimates and $t$-statistics of the parameters in the mean equation (estimates from the variance equation are not reported here since they are less important for our purposes in this paper). The $t$-statistics were generated based on the heteroskedasticity and autocorrelation consistent Newey-West (1987) standard errors with 12 lags. We also present the log likelihood ratios from the maximization procedures.

First, consider the results for the day-of-the-week effect. The estimated coefficients for Monday and Tuesday were significantly negative at the $5 \%$ level, which is consistent with the results in Table 1. The Friday return coefficient is not significant. Clearly, the South African stock market is characterized by Monday and Tuesday effects. Worthington (2010) also documented lower returns for Tuesday in 
the Australian stock market, but he reported similar returns for Monday and Wednesday. In contrast, Alagidede (2008a) reported significant positive Monday returns and marginally significantly negative Friday returns. The differences in our results and those of Alagidede's are likely due to variations in sample periods. We used a more comprehensive sample from 1973-2012, while his study used a much shorter period (2001-2006).

Regarding our results for the beginning-of-the-month effect, previous research in the literature suggests that the first trading day of a given month has a higher return compared to other trading days of the month. However, the evidence in Table 2 is inconsistent with this notion. Aside from the second and third trading days, return on the first trading day of a given month is not different from returns in other trading days which accords with the finding of Worthington (2010) in the Australian market. In contrast, the second and third trading days of the month exhibit significantly higher returns relative to returns in other trading days. The estimated coefficients of the second and third trading days were 0.207 and 0.121 , respectively, and both were statistically significant at the $5 \%$ level. It is possible that the positive and highly significant effect of the second and third trading days (rather than the first trading day) is due to the delayed impact of the US market on the Johannesburg Stock Exchange (see Worthington, 2010).

The presence of seasonal anomalies may suggest market inefficiency as they open the possibility of formulating profitable trading rules based on seasonal patterns. For example, day traders can form portfolios at the end of first trading day, and then sell them at the end of the third trading day in each month to achieve abnormal profits. Similarly, traders may designate Mondays and Tuesdays as the buying (not selling) days of the week since the results indicate stock prices in these two days are the lowest in the week.

Turning to the month-of-the-year effect, we failed to find any significant daily return in any month. Taking July as the benchmark month, the daily returns in any months other than July were not statistically different from the returns in July. This finding is similar to the evidence from Coutts and Shejkhj (2002). Nevertheless, several studies support the presence of either a January or December effect. Consequently, we included January and December dummies to investigate whether their returns were indeed different from those in other months in the South African market. The results in columns (7) and (8) of Table 2 buttress our finding in that the dummy coefficients of January and December did not achieve statistical significance at the $5 \%$ level. 
Finally, considering an overall calendar effect (combining the effects of day-of-the-week, beginning-of-the-month and month-of-the-year), we report the results in Table 2 . The evidence on a combined seasonal effect is broadly consistent with the findings for the individual effects: Monday and Tuesday have lower returns, while the second trading days generally have higher returns compared to other days.

We also checked whether our regression results possess the desirable property of structural stability. Following Farley, Hinich, \& McGuire (1975) and Darrat, Li, Liu, \& Su (2012), we divided our sample at various breaking dates and inspected the sub-sample regressions. Table 3 displays the results. As seen in column (1) of Table 3, returns in the early period (1973-1992) for Monday and Tuesday are much lower than Wednesday return. For example, on average, the daily return on Monday was $0.319 \%$ lower than the return on Wednesday, and Friday return is significantly less than the Wednesday return. The December effect has also vanished in this earlier period. In the latter period (1993-2012), column (3) reveals that the day-of-the-week effect disappears, but the beginning-of-the-month effect remains strong. Like our evidence from the full period, the results for the latter period in column (3) reject the January effect, but marginally support a positive December effect that is $0.158 \%$ higher than returns in July. Such persistent support for the December effect accords well with the evidence reported by Darrat, Li, Liu, \& Su (2012) for several markets. The positive December effect in the later period may be due to investors buying more stocks in December in the anticipation of "higher stock prices" during the following month of January and it may also be attributed to extending the Christmas shopping mood to the stock market as discussed in Darrat, Li, Liu, \& Su (2012).

Furthermore, Table 3 reports findings from testing the sensitivity of our results to the recent global financial crisis (GFC) that started in 2008. Similar to our conclusions from the full sample period, the results over the pre-GFC period suggest that the Monday and Tuesday coefficients are significantly negative, and the second and the third trading day coefficients are significantly positive. However, over the post-GFC period, neither the coefficients of Monday and Tuesday nor those for the second and third trading day proved to be statistically significant even at the weak $10 \%$ level. It appears that the recent global financial crisis may have mitigated the presence of significant seasonal patterns in the Johannesburg stock market.

Since South Africa joined the BRIC group in December 2011, it would be interesting to see if there was any seasonal pattern in stock returns in 2011-2012. Since this only spans 21 months, there are not enough independent observations to estimate the beginning-of-the-month and month coefficients. Columns (9) and (10) of 
Table 3 report the results where we estimate equation (2) over the period from January 3, 2011 to September 28, 2012. Similar to our earlier results for the post-GFC period, there is no significant support for a day-of-the-week effect.

\section{CONCLUSION}

This paper examined the presence of seasonal anomalies in the Johannesburg Stock Exchange using daily data over the period spanning from 1973 to 2012. We tested three seasonal effects: day-of-the-week, beginning-of-the-month, and month-of-the-year. We found no compelling support for either a January or December effect in the case of the South African market. However, the evidence strongly indicates the presence of robust Monday and Tuesday effects, whereby the returns on Monday and Tuesday are significantly lower than the return on the benchmark day of Wednesday. Moreover, a beginning-of-the-month effect is also quite pronounced in which second and third trading day returns are significantly larger than returns in other trading days. Nevertheless, such significant day-of-the-week and beginning-of-the-month seasonal effects disappear in the post-2008 period following the global financial crisis. It can thus be concluded that the South African stock market may have filtered out seasonal anomalies and become more efficient in the aftermath of the recent global financial crisis.

\section{ACKNOWLEDGEMENT}

Bin Li thanks Griffith Business School for financial support under the 2012 Griffith Business School Internal Research Grant. 


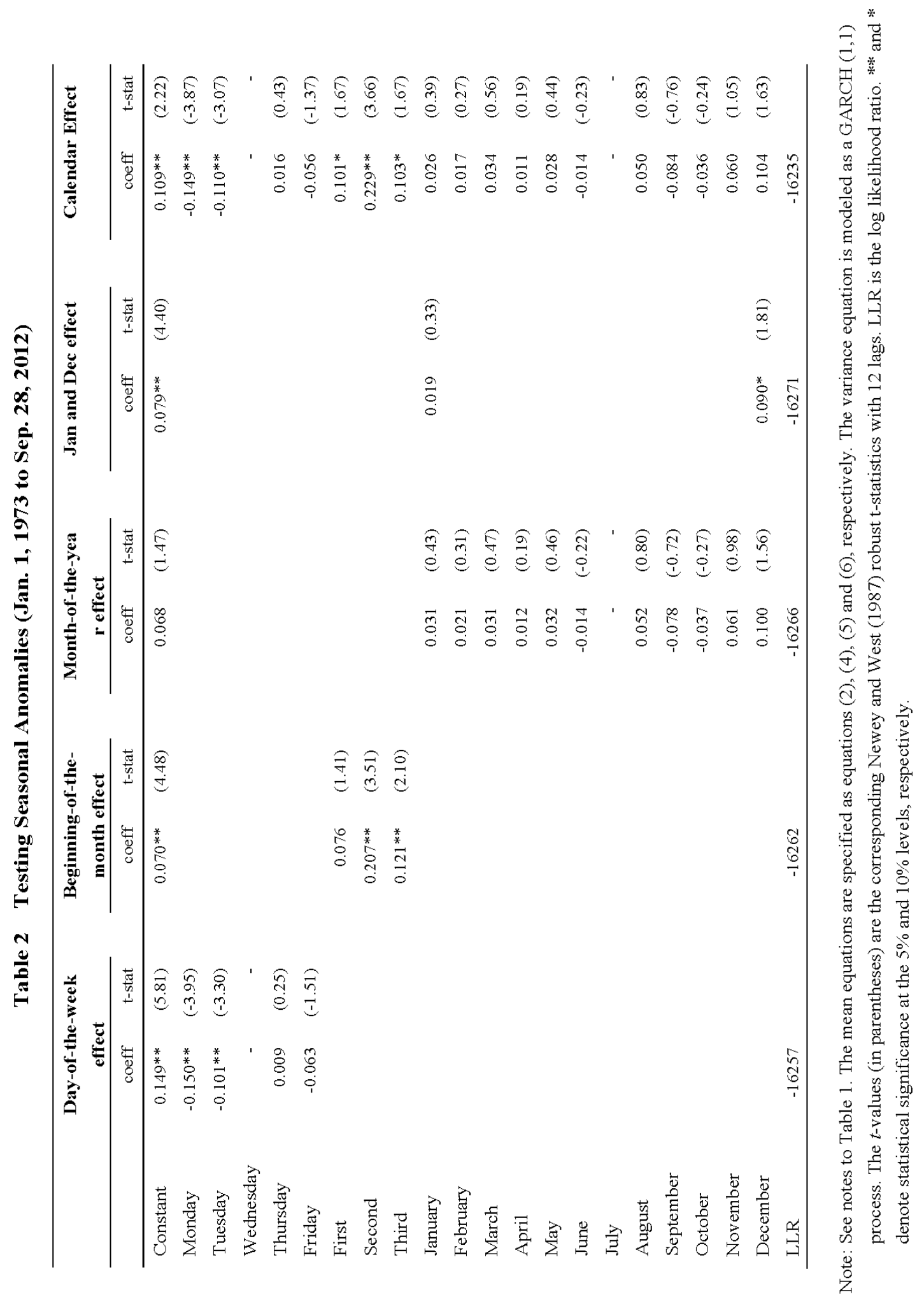




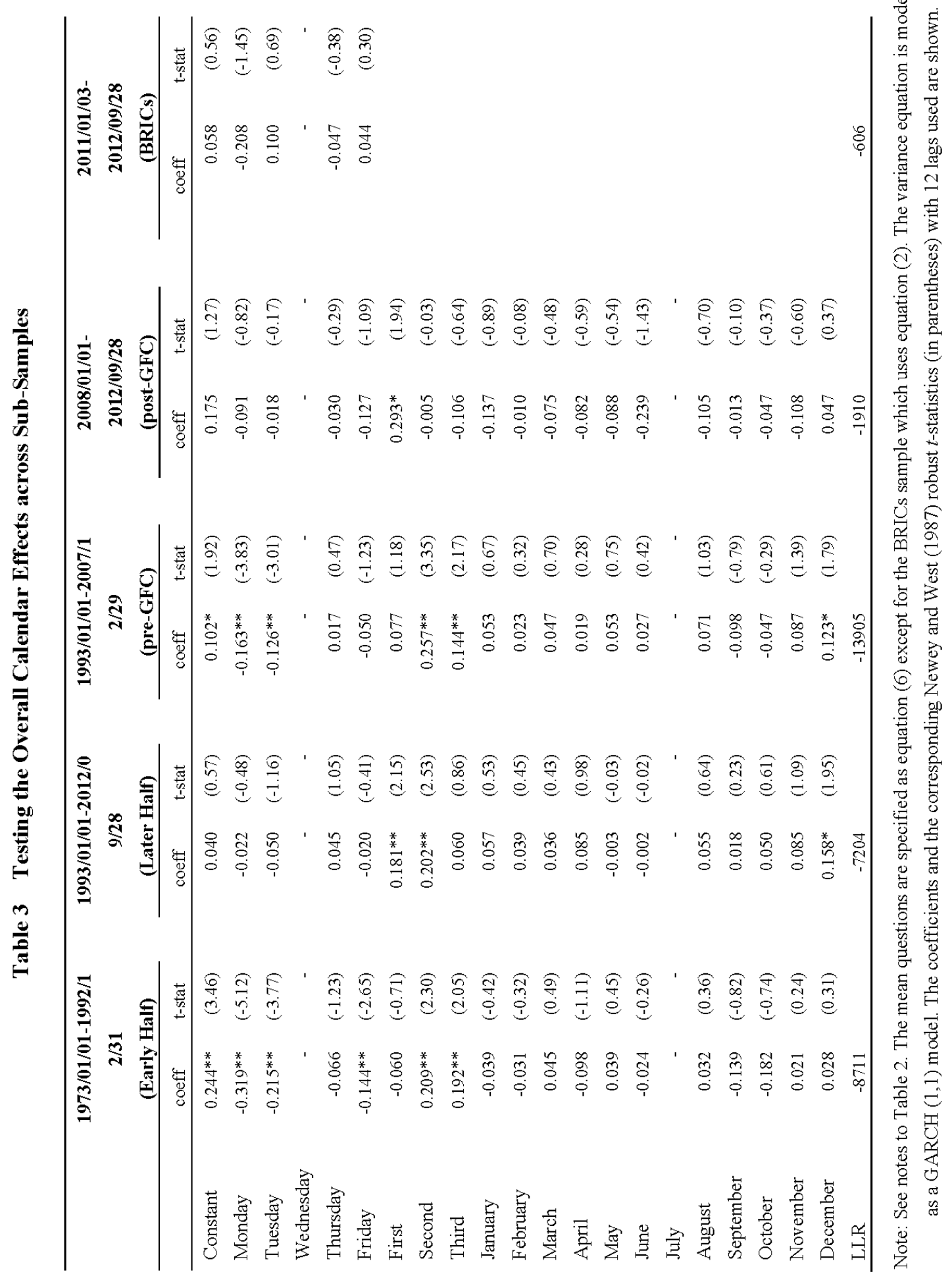




\section{REFERENCES}

Alagidede, P. (2008a). Day of the week seasonality in African stock markets. Applied Financial Economics Letters, 4(2), 115-120. http://dx.doi.org/10.1080/17446540701537749

Alagidede, P. (2008). Month-of-the-year and pre-holiday seasonality in African stock markets. University of Stirling Economics Discussion Paper 2008-23. Retrieved from https://dspace.stir.ac.uk/handle/1893/523

Ariel, R.A. (1987). A monthly effect on stock returns. Journal of Financial Economics,18(1), 161-174. http://dx.doi.org/10.1016/0304-405X(87)90066-3

Baden, Ben. (2010, August 26). 12 Reasons to Invest in Africa. US News \& World Report. Retrieved from http://money.usnews.com/money/personal-finance/ mutual-funds/articles/2010/08/26/12-reasons-to-invest-in-africa

Cho, Y.H., Linton, O. \& Whang, Y.J. (2007). Are there Monday effects in stock returns: A stochastic dominance approach. Journal of Empirical Finance, 14(5), 736-755. http://dx.doi.org/10.1016/j.jempfin.2007.02.001

Coutts, J.A. \& Sheikh, M.A. (2002). The anomalies that aren't there: the weekend, January and pre-holiday effects on the all gold index on the Johannesburg Stock Exchange 1987-1997. Applied Financial Economics, 12(12), 863-871. http://dx.doi.org/10.1080/09603100110052172

Darrat A.F., Li, B., Liu, B. \& Su, J.J. (2012). A fresh look at seasonal anomalies: an international perspective. International Journal of Business and Economics, forthcoming, 10(2), 93-116.

Dzhabarov, C. \& Ziemba, W.T. (2010). Do seasonal anomalies still work?. Journal of Portfolio Management, 36, 93-104. http://dx.doi.org/10.3905/jpm.2010.36.3.093

Farley, J.U., Hinich, M.J. \& McGuire, T.W. (1975). Some comparisons of tests for a shift in the slopes of a multivariate linear time series model. Journal of Econometrics, 3(3), 297-318. http://dx.doi.org/10.1016/0304-4076(75)90037-8

Gultekin, M. \& Gultekin, B. (1983). Stock market seasonality: international evidence. Journal of Financial Economics, 12(4), 469 - 482. Retrieved from http://www2.stetson.edu/fsr/abstracts/vol_6_num1_p19.pdf

Jaffe, J. \& Westfield, R. (1985). Patterns in Japanese common stock returns: day of the week and turn of the year. Journal of Financial and Quantitative Analysis, 20 (2), 261-272. http://dx.doi.org/10.2307/2330959

Johannesburg Stock Exchange. (2012, December 30). Overview of JSE. Retrieved from http://www.jse.co.za/About-Us/Overview-of-the-JSE.aspx 
Keim, D. \& Stambaugh, R. (1984). A Further investigation of the weekend effect in stock returns. Journal of Finance, 39(3), 819-835. http://dx.doi.org/10.1111/j.1540-6261.1984.tb03675.x

Kemmerer, F.W. (1911). Seasonal variations in the New York money market. American Economic Review, 1(1), 33-49.

Lucey, B.M. (2001). Friday the 13th: International evidence. Applied Economics Letters, 8(9), 577-579. http://dx.doi.org/10.1080/13504850010025664

Newey, W.K. \& West, K.D. (1987). A simple, positive semi-definite, heteroskedasticity and autocorrelation consistent covariance matrix. Econometrica, 55(3), 703-708. http://dx.doi.org/10.2307/1913610

Sun, Q. \& Tong, W.H.S. (2010). Risk and the January effect. Journal of Banking \& Finance, 34(5), 965-974. http://dx.doi.org/10.1016/j.jbankfin.2009.10.005

Tonchev, D. \& Kim, T.H. (2004). Calendar effects in Eastern European financial markets: Evidence from the Czech Republic, Slovakia and Slovenia.

Applied Financial Economics, 14(14), 1035-1043. http://dx.doi.org/10.1080/0960310042000264003

Worthington, A.C. (2010). The decline of calendar seasonality in the Australian stock exchange, 1958-2005. Annals of Finance, 6(3), 421-433. 
